\title{
ANALISIS KEPUASAN MAHASISWA TERHADAP PELAYANAN UNIKA DE LA SALLE MANADO MENGGUNAKAN METODE IMPORTANCE PERFORMANCE ANALYSIS
}

\author{
Zergio R. I. Mautofani ${ }^{1}$, Prudensy F. Opit ${ }^{2}$, Ronaldo Rottie ${ }^{3}$ \\ ${ }^{1,2,3)}$ Fakultas Teknik, Program Studi Teknik Industri, Universitas Katolik De La Salle Manado \\ Kairagi I Kombos Manado \\ Email: zergiomautofani@gmail.com, popit@unikadelasalle.ac.id, rrottie@unikadelasalle.ac.id
}

\begin{abstract}
Abstrak
Universitas Katolik De La Salle merupakan institusi swasta yang bergerak di bidang pendidikan. Universitas Katolik De La Salle Manado mempunyai 3059 mahasiswa, konsekuensinya pihak universitas harus meningkatkan pemberian pelayanan terbaik bagi para mahasiswa yang ada, agar mahasiswa yang ada tidak merasa kecewa dengan pelayanan yang di berikan oleh pihak universitas. Pada Tugas Akhir ini akan mengukur dan mengidentifikasi atirubtatribut apa saja yang memperngaruhi kepuasan pelanggan, dalam hal ini adalah mahasiswa, tools yang digunakan ada 2 jenis, yang pertama kuesioner pendahuluan sebagai acuan untuk pembuatan instrumen penelitian, dan kuesioner penelitian yang sudah berisikan atribut-atribut yang akan di isi oleh responden. Metode yang digunakan dalam penelitian ini adalah Importance Performance Analysis (IPA). Berdasarkan hasil analisis menggunakan metode Importance Performance Analysis, didapatkan bahwa ada 5 atribut yang harus dijadikan prioritas. Atribut-atribut yang harus dijadikan prioritas oleh pihak universitas adalah sebagai berikut, ketersediaan sarana prasarana non akademik yang memadai, kenyamanan pada saat pelayanan administrasi akademik, penyimpanan arsip atau dokumen mahasiswa dengan baik dan terstruktur, pelayanan yang cepat dan tepat, dan pelayanan yang santun di beberapa bagian.
\end{abstract}

Kata kunci: Kepuasan Pelanggan, Atribut, Importance Performance Analysis (IPA)

Abstract
De La Salle Catholic University is a private institution in the field of education. Catholic University De La Salle of Manado has 3059 students, consequently parties should increase the University awarding the best service for the students, so students there do not feel disappointed with the service given by the University. In this final project will quantify and identify the attributes anything that affects customer satisfaction, in this case are students, tools used there are two types, the first preliminary questionnaire as a reference for the manufacture of instruments of research, and the research questionnaire already contains attribute-attribute to befilled in by the respondent. The methods used in this research is the Importance Performance Analysis (IPA). Based on the results of the analysis using the method of Importance Performance Analysis, obtained that there are 5 attributes that should be made a priority. Attributes that should be made a priority by the University is as follows, the availability of adequate academic infrastructure, the availability of infrastructure of non adequate academic, comfort at the time of service of academic administration, student or document archive storage and structured, fast service and prompt, courteous service and in some parts.

Keyword: Customer Satisfaction, Attribute, Importance Performance Analysis.

\section{PENDAHULUAN}

Perkembangan teknologi yang terjadi saat ini menyebabkan perubahan pandangan para pelanggan terhadap perusahaan penyedia jasa. Banyak perusahaan berusaha meningkatkan daya saing untuk menarik pelanggan, dan tentunya memberikan pelayanan terbaik bagi para pelanggannya untuk menjaga royalitas para pelanggan. Tidak hanya perusahaan penyedia jasa, perguruan tinggi swasta juga harus memperhatikan kepuasan pelanggan dalam hal ini adalah mahasiswa, dengan memberikan pelayanan terbaik, agar dapat meningkatkan daya saing. Universitas Katolik De La Salle Manado mempunyai 3059 mahasiswa, konsekuensinya pihak universitas harus meningkatkan pemberian pelayanan terbaik bagi para mahasiswa yang ada, agar mahasiswa yang ada tidak merasa kecewa dengan pelayanan yang di berikan oleh pihak universitas. Hingga saat ini pengukuran kepuasan mahasiswa terhadap pelayanan universitas tidak dilakukan, sehingga tingkat kepuasan mahasiswa tidak diketahui. Berdasarkan wawancara yang dilakukan dengan sejumlah mahasiswa, mahasiswa sering mengeluhkan tentang fasilitas yang disediakan universitas, dan juga pelayanan yang kurang baik di beberapa bagian seperti bagian akademik, dan bagian keuangan yang ada di Universitas Katolik De La Salle Manado. Berdasarkan masalah yang ada, maka perlu dilakukan pengukuran terhadap kepuasan pelanggan dalam hal ini adalah mahasiswa, dengan menggunakan metode Importance Performance Analysis (IPA) untuk meningkatkan pelayanan dan kinerja yang ada di 
Universitas Katolik De La Salle Manado. Berdasarkan data yang dikumpulkan melalui penyebaran kuesioner tentang tingkat kepentingan dan penilaian kinerja, maka dapat ditentukan tingkat kesesuaian untuk menentukan urutan prioritas dan peningkatan pelayanan Universitas Katolik De La Salle Manado yang dapat mempengaruhi kepuasan pelanggan atau dalam hal ini adalah mahasiswa.

\section{LANDASAN TEORI}

\subsection{Penentuan Sampel Penelitian}

Melakukan penelitian pada suatu populasi, sering menggunakan sampel untuk mewakili populasi tersebut. Hal ini dikarenakan penelitian dengan menggunakan populasi secara keseluruhan akan memakan waktu yang lama dan biaya yang sangat besar. Secara definisi, populasi dapat diartikan sebagai jumlah dari keseluruhan obyek yang ingin diteliti karakteristiknya. Sampel tersebut dianggap dapat mewakili keseluruhan populasinya.

Agar sampel yang kita ambil dapat benarbenar mewakili populasinya, kita perlu suatu standar ataupun cara dalam menentukan sampel, salah satunya adalah menggunakan rumus yang dikemukakan oleh Slovin yang sederhana dan mudah dihitung [1]. Secara matematis, rumus Slovin yang kita gunakan untuk menentukan jumlah sampel adalah sebagai berikut:

$$
n=\frac{N}{1+\left(N e^{2}\right)}(\mathrm{i})
$$

\subsection{Importance Performance Analysis (IPA)}

Penelitian yang dilakukan ini menggunakan metode Importance performance Analysis (IPA) untuk mengukur tingkat kepuasan pelanggan dalam hal ini mahasiswa. Pembobotan menggunakan skala likert sebagai berikut :

- Tingkat kepentingan pelanggan :

1. Bobot nilai 5, Sangat Penting

2. Bobot nilai 4, Penting

3. Bobot nilai 3, Cukup penting

4. Bobot nilai 4 , Tidak penting

5. Bobot nilai 5, Sangat tidak penting

- Tingkat kinerja perusahaan :

1. Bobot nilai 5, Sangat baik

2. Bobot nilai 4, Baik

3. Bobot nilai 3, Cukup baik

4. Bobot nilai 2, Tidak baik

5. Bobot nilai 1, Sangat tidak baik

Metode Importance Performance Analysis (IPA) merupakan suatu teknik penerapan yang mudah untuk mengatur atribut dari tingkat kepentingan dan tingkat pelaksanaan itu sendiri.

Pada metode ini diperlukan pengukuran tingkat kesesuaian untuk mengetahui seberapa besar pelanggan merasa puas terhadap kinerja perusahaan, dalam hal ini pelanggan merupakan mahasiswa yang akan menilai kinerja dari universitas. Rumus yang digunakan adalah sebagai berikut:

$$
\begin{aligned}
& \overline{X \imath}=\frac{\sum_{i=1}^{k} X i}{n} \text { (ii) } \\
& \bar{Y} \iota=\frac{\sum_{i=1}^{k} Y i}{n} \text { (iii) }
\end{aligned}
$$

Keterangan:

$\overline{X \imath}=$ skor rata-rata tingkat kinerja

$\bar{Y} l=$ skor rata-rata tingkat kepentingan

$\mathrm{n}=$ banyaknya sampel penelitian

tahap berikutnya mencari skor kesesuaian perbandingan antara skor kepentingan dan skor kinerja dengan persamaan sebagai berikut:

Keterangan:

$$
T_{k i}=\frac{X i}{Y i} \times 100 \% \text { (iv) }
$$

$T_{k i}=$ tingkat kesesuaian

$X i=$ skor penilaian kinerja perusahaan

$Y i=$ skor penilaian kepentingan pelanggan

Setelah dilakukan pengukuran tingkat kesesuaian, langkah selanjutnya adalah membuat peta posisi importance-performance yang merupakan suatu bangun yang dibagi menjadi empat kuadran yang dibatasi oleh dua buah garis berpotongan tegak lurus pada titik-titik [2] sebagai berikut:

$$
\begin{aligned}
& \overline{\bar{X}}=\frac{\sum_{i=1} \overline{X l}}{K}(\mathrm{v}) \\
& \overline{\bar{Y}}=\frac{\sum_{i=1} \overline{Y l}}{K}(\mathrm{vi})
\end{aligned}
$$

Keterangan:

$\overline{\bar{X}}=$ nilai rata-rata atribut kinerja perusahaan

$\overline{\bar{Y}} l=$ nilai rata-rata atribut kepentingan pelanggan

$\mathrm{K}=$ jumlah atribut yang mempengaruhi kepuasan pelanggan.

Teknik ini dikemukakan pertama kali oleh Martilla dan James pada tahun 1977 dalam artikel mereka "Importance-Performance Analysis" yang dipublikasikan di Journal of Marketing. Pada teknik ini, responden diminta untuk menilai tingkat kepentingan dan kinerja perusahaan, kemudian nilai rata-rata tingkat kepentingan dan kinerja tersebut dianalisis pada Importance-Performance Matrix, yang mana sumbu x mewakili persepsi 
sedangkan sumbu y mewakili harapan, maka nanti akan didapat hasil berupa empat kuadran sesuai gambar berikut:

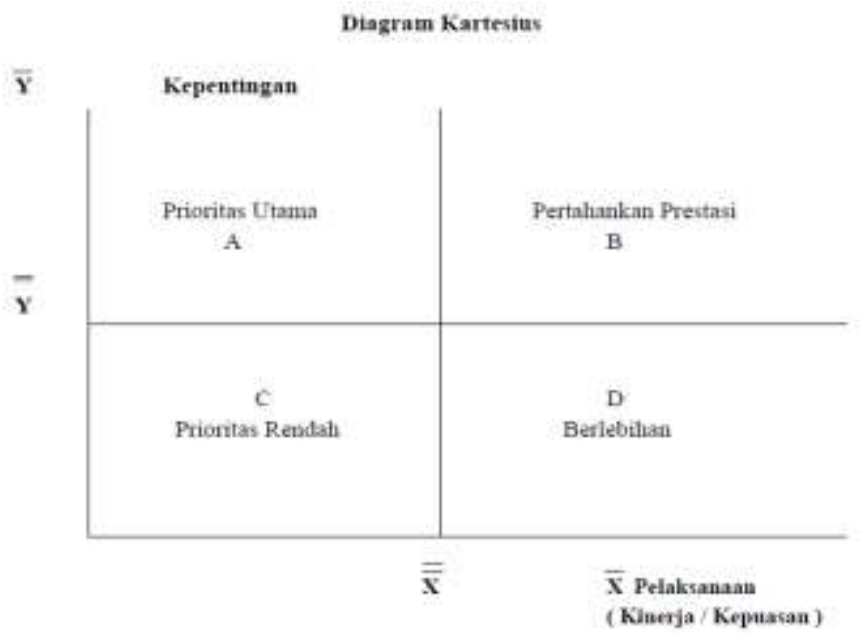

Gambar 1. Diagram Kartesius

Adapun interpretasi dari kuadran tersebut adalah sebagai berikut:

A. Prioritas Utama (Concentrate Here)

Pada kuadran ini terdapat faktor-faktor yang dianggap penting dan atau diharapkan konsumen, akan tetapi kinerja perusahaan dinilai belum memuaskan sehingga pihak perusahaan perlu berkonsentrasi untuk mengalokasikan sumber dayanya, guna meningkatkan performa yang masuk pada kuadran ini.

B. Pertahankan Prestasi (Keep Up The Good Work)

Pada kuadaran ini terdapat faktor-faktor yang dianggap penting dan diharapkan sebagai faktor penunjang kepuasan konsumen sehingga perusahaan wajib untuk mempertahankan prestasi kinerja tersebut.

C. Prioritas Rendah (Low Priority)

Pada kuadaran ini terdapat faktor-faktor yang dianggap mempunyai tingkat persepsi atau kinerja aktual yang rendah dan tidak terlalu penting dan atau tidak terlalu diharapkan oleh konsumen, sehingga perusahaan tidak perlu memprioritaskan atau memberikan perhatian lebih pada faktor-faktor tersebut.

D. Berlebihan (Possibly Overkill)

Pada kuadaran ini terdapat faktor-faktor yang dianggap tidak terlalu penting dan tidak terlalu diharapkan oleh pelanggan, sehingga perusahaan lebih baik mengalokasikan sumber daya yang terkait pada faktor tersebut kepada faktor lain yang lebih memiliki tingkat prioritas lebih tinggi [3].

\section{METODOLOG PENELITIAN \\ 3.1 Kerangka Pemecahan Masalah}

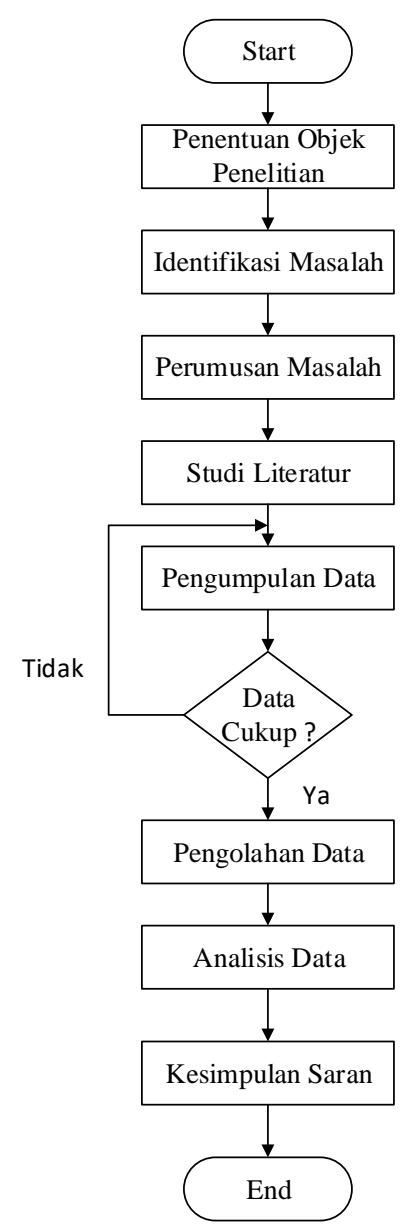

Gambar 2. Kerangka Pemecahan Masalah

Tahap-tahap penelitian dilakukan sesuai dengan Gambar 2 dengan uraian sebagai berikut:

1. Penentuan Objek Penelitian

Penentuan objek penelitian merupakan tahap awal dari penelitian ini, dimana Universitas Katolik De La Salle Manado dipilih sebagai tempat penelitiannya.

2. Identifikasi Masalah

Setelah penentuan objek penelitian, lalu dilakukan pengidentifikasian masalah terhadap objek yang akan diteliti

3. Perumusan Masalah

Setelah mengidentifikasi masalah yang akan diteliti, tahap selanjutnya adalah merumuskan masalah yang akan diteliti

4. Studi Literatur

Tahap selanjutnya melakukan studi literatur yang berhubungan dengan kepuasan pelanggan dan metode yang akan digunakan yaitu Importance Performance Analysis, untuk 
membantu dan menambah pemahaman lebih lanjut terhadap penelitian yang dilakukan

5. Pengumpulan Data

Setelah melakukan studi literature, tahap selanjutnya adalah pengumpulan data yang berkaitan dengan penelitian ini yang nantinya akan diolah sehingga mendapatkan solusi dari perumusan masalah. Ada beberapa tahap pengumpulan data sebagai berikut :

- Wawanacra, wawancara dilakukan dengan menggunakan kuesioner pendahuluan sebagai tools, untuk mengetahui atribut-atribut apa yang nantinya akan di isi dalam kuesioner penelitian

- Penyusunan Instrumen, dari hasil wawancara ditentukan instrument-instrumen apa saja yang akan dipakai dalam kuesioner.

- Penyebaran Kuesioner, sebelum menyebarkan kuesioner, hal yang harus dilakukan adalah menghitung berapa jumlah sampel yang akan di ambil dari total populasi dengan menggunakan persamaan yang dikemmukakan oleh Slovin yang dikutip dari elektronika.com sebagai berikut :

Keterangan :

$$
n=\frac{N}{1+\left(N e^{2}\right)}
$$

$\mathrm{n}$ = Besar sampel untuk penelitian

$\mathrm{N}=$ Ukuran populasi

$\mathrm{e}=$ Persen kelonggaran ketidaksesuaian pengambilan sampel masih ditoleransi.

6. Pengolahan data

Tahap selanjutnya pengolahan data yang sudah ada dengan menggunakan metode Importance Performance Analysis. Pengolahan pada penelitian ini terdiri dari beberapa tahap, sebagai berikut :

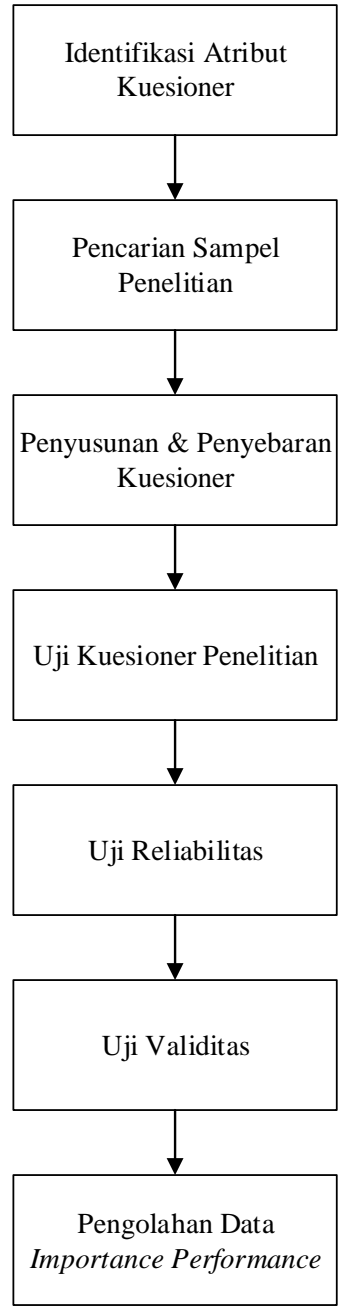

\section{Gambar 4. Langkah-langkah pengolahan data}

- Identifikasi atribut kuesioner, sebelum membuat kuesioner penelitian, hal pertama yang dilakukan adalah mengidentifikasi atribut apa yang hendak dipakai untuk kuesioner penelitian.

- Pencarian sampel, mencari berapa banyak sampel yang akan diteliti

- Penyusunan dan penyebaran kuesioner, penyusunan kuesioner dilakukan dengan mengikuti 5 dimensi yang dikemukakan oleh Parasuraman et al dan juga dari hasil identifikasi kuesioner pendahuluan. Penyebaran kuesioner menggunakan teknik pengambilan sampel secara acak sederhana atau simple random sampling. Menurut Hasan yang dikutip dari Wahyuningsih (2012), sampel acak sederhana adalah setiap elemen memiliki peluang yang sama untuk dipilih sebagai sampel. Sampel acak sederhana dapat 
digunakan apabila dalam satu populasi bersifat homogen.

- Menguji validitas data, pada tahap ini kita menguji untuk mengetahui apakah data yang ada valid atau tidak.

- Menguji reliabilitas data, pada tahap ini kita menguji apakah data relibel atau tidak

- Gambaran umum responden, setelah data diuji validitas dan reliabilitasnya, selanjutnya dilakukan pengujian untuk melihat gambaran umum dari responden berupa jenis kelamin, umur, dll.

- Mengolah data IPA

7. Analisis Data

Tahap selanjutnya adalah analisis data, dimana setelah dilakukan pengolahan data, hasil dari pengolahan data di analisis untuk mendapatkan hasil.

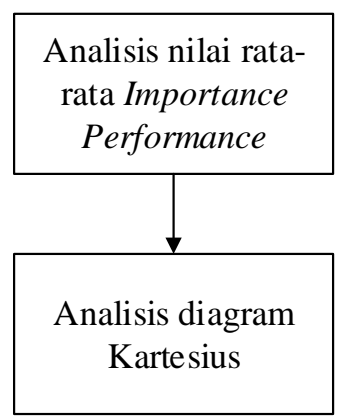

Gambar 5. Langkah-langkah analisis

- Menganalisis nilai rata-rata dari seluruh atribut Importance dan Performance

- Membuat diagram kartesius untuk mengetahui atribut-atribut apa saja yang masuk di dalam kuadran A (prioritas), kuadran B (pertahankan prestasi), kuadran C (prioritas rendah), kuadran D (berlebihan).

\section{Kesimpulan dan Saran}

Tahap terakhir dari penelitian ini adalah penarikan kesimpulan berdasarkan pengolahan dan analisis data, dan menjawab tujuan yang ingin dicapai dalam penelitian ini. Selain itu diberikan masukan bagi universitas berdasarkan hasil penelitian, khususnya untuk meningkatkan pelayanan dan kinerja.

\section{ANALISIS \& PEMBAHASAN}

\subsection{Penentuan Sampel}

Sebelum menyebarkan kuesioner, hal yang harus dilakukan adalah menghitung berapa jumlah sampel yang akan di ambil dari total populasi mahasiswa aktif yang ada di Universitas Katolik De La Salle Manado, jumlah populasi dilihat pada Pangkalan Data Perguruan Tinggi DIKTI, populasi mahasiswa aktif yang ada di Universitas Katolik De La Salle Manado adalah sebanyak 3059 mahasiswa. Perhitungan untuk mencari sampel menggunakan persamaan (2.1) :

$$
\begin{aligned}
& \mathrm{n}=\frac{3059}{1+\left(3059 \times 0,1^{2}\right)} \\
& \mathrm{n}=96,833 \approx 100
\end{aligned}
$$

sampel yang akan di ambil pada penelitian ini adalah sebanyak 100 dari 3059 mahasiswa, dengan menggunakan tingkat toleransi error sebesar $(10 \%)$.

\subsection{Uji Validitas}

Nilai $\mathrm{r}$ tabel pada tabel product moment adalah 0,3061. Kuesioner di sebar kepada seluruh responden sesuai dengan sampel yang di dihitung, setelah data dari hasil penyebaran kuesioner terkumpul, maka selanjutnya dilakukan pengujian validitas terhadap setiap pernyataan yang ada, apakah pernyataan yang ada valid atau tidak valid. Pernyataan yang valid dipakai dalam penelitian dan pernyataan yang tidak valid di eleminasi, dan tidak dipakai lagi. Untuk hasil dari pengujian validitas dapat dilihat pada tabel 1 .

\begin{tabular}{|c|c|c|c|c|c|}
\hline Dimensi & $\begin{array}{l}\text { Atri } \\
\text { but }\end{array}$ & $\begin{array}{c}\text { r hitung } \\
\text { (Perform } \\
\text { ance) (Xi) }\end{array}$ & $\begin{array}{l}\text { r hitung } \\
\text { (Importa } \\
\text { nce) (Yi) }\end{array}$ & $\begin{array}{c}r \\
\text { tabe } \\
\text { I }\end{array}$ & $\begin{array}{c}\text { Keteran } \\
\text { gan }\end{array}$ \\
\hline \multirow{4}{*}{$\begin{array}{c}\text { Bukti } \\
\text { Langsung } \\
\text { (Tangible) }\end{array}$} & 1 & 0.704 & 0.347 & $\begin{array}{c}0.30 \\
61\end{array}$ & Valid \\
\hline & 2 & 0.799 & 0.687 & $\begin{array}{c}0.30 \\
61\end{array}$ & Valid \\
\hline & 3 & 0.778 & 0.250 & $\begin{array}{c}0.30 \\
61\end{array}$ & $\begin{array}{l}\text { Tidak } \\
\text { Valid }\end{array}$ \\
\hline & 4 & 0.657 & 0.453 & $\begin{array}{c}0.30 \\
61\end{array}$ & Valid \\
\hline \multirow{4}{*}{$\begin{array}{l}\text { Kehandalan } \\
\text { (Reliability) }\end{array}$} & 5 & 0.811 & 0.715 & $\begin{array}{c}0.30 \\
61\end{array}$ & Valid \\
\hline & 6 & 0.836 & 0.541 & $\begin{array}{c}0.30 \\
61\end{array}$ & Valid \\
\hline & 7 & 0.790 & 0.486 & $\begin{array}{c}0.30 \\
61\end{array}$ & Valid \\
\hline & 8 & 0.705 & 0.584 & $\begin{array}{c}0.30 \\
61\end{array}$ & Valid \\
\hline \multirow{2}{*}{$\begin{array}{c}\text { Ketanggapa } \\
\mathrm{n} \\
\text { (Responsiv } \\
\text { eness) }\end{array}$} & 9 & 0.535 & 0.162 & $\begin{array}{c}0.30 \\
61\end{array}$ & $\begin{array}{l}\text { Tidak } \\
\text { Valid }\end{array}$ \\
\hline & 10 & 0.742 & 0.539 & $\begin{array}{c}0.30 \\
61\end{array}$ & Valid \\
\hline
\end{tabular}

Tabel 1. Hasil Uji Validitas 


\begin{tabular}{|c|c|c|c|c|c|}
\hline Dimensi & $\begin{array}{l}\text { Atri } \\
\text { but }\end{array}$ & $\begin{array}{c}r \text { hitung } \\
\text { (Perform } \\
\text { ance) (Xi) }\end{array}$ & $\begin{array}{l}\text { r hitung } \\
\text { (Importa } \\
\text { nce) (Yi) }\end{array}$ & $\begin{array}{c}r \\
\text { tabe } \\
\text { I }\end{array}$ & $\begin{array}{c}\text { Keteran } \\
\text { gan }\end{array}$ \\
\hline & 11 & 0.673 & 0.501 & $\begin{array}{c}0.30 \\
61\end{array}$ & Valid \\
\hline & 12 & 0.735 & 0.637 & $\begin{array}{c}0.30 \\
61\end{array}$ & Valid \\
\hline \multirow{4}{*}{$\begin{array}{c}\text { Jaminan } \\
\text { (Assurance) }\end{array}$} & 13 & 0.704 & 0.642 & $\begin{array}{c}0.30 \\
61\end{array}$ & Valid \\
\hline & 14 & 0.854 & 0.557 & $\begin{array}{c}0.30 \\
61\end{array}$ & Valid \\
\hline & 15 & 0.590 & 0.548 & $\begin{array}{c}0.30 \\
61\end{array}$ & Valid \\
\hline & 16 & 0.786 & 0.863 & $\begin{array}{c}0.30 \\
61\end{array}$ & Valid \\
\hline \multirow{4}{*}{$\begin{array}{c}\text { Empati } \\
\text { (Empathy) }\end{array}$} & 17 & 0.745 & 0.904 & $\begin{array}{c}0.30 \\
61\end{array}$ & Valid \\
\hline & 18 & 0.802 & 0.789 & $\begin{array}{c}0.30 \\
61\end{array}$ & Valid \\
\hline & 19 & 0.823 & 0.814 & $\begin{array}{c}0.30 \\
61\end{array}$ & Valid \\
\hline & 20 & 0.856 & 0.561 & $\begin{array}{c}0.30 \\
61\end{array}$ & Valid \\
\hline
\end{tabular}

Berdasarkan hasil uji validitas yang telah dilakukan, ada 2 atribut yang tidak valid. Berikut adalah atribut yang tidak valid dan tidak akan digunakan pada penelitian ini, yaitu :

1. Atribut 3: Kebersihan Fasilitas

2. Atribut 9 : Universitas menyediakan dosen pembimbing

\subsection{Uji Reliabilitas}

Menguji reliabilitas dilakukan untuk mengetahui ketepatan alat ukur tersebut dalam menjalankan fungsinya. Reliabilitas suatu alat ukur dikatakan reliabel apabila nilai Cronbach's Alpha $>0,60$. Pengujian reliabilitas menggunakan software IBM SPSS Statistic 24, dengan hasil untuk tingkat kepentingan adalah 0,907 dan untuk tingkat pelayanan/kinerja adalah 0,956 . Untuk nilai Cronbach's Alpha dari masing-masing atribut yang ada dapat dilihat pada tabel 4 .

Tabel 2. Nilai Cronbach's Alpha Importance

\begin{tabular}{|r|r|}
\hline Cronbach's Alpha & N of ltems \\
\hline .907 & 18 \\
\hline
\end{tabular}

\begin{tabular}{|r|r|}
\hline Cronbach's Alpha & Nof ltems \\
\hline .956 & 18 \\
\hline
\end{tabular}

Tabel 4. nilai Cronbach's Alpha masingmasing Atribut

\begin{tabular}{|c|c|c|c|c|}
\hline Dimensi & $\begin{array}{c}\text { Alpha } \\
\text { Cronbach } \\
\text { (Performa } \\
\text { nce) }\end{array}$ & $\begin{array}{c}\text { Alpha } \\
\text { Cronbac } \\
h \\
\text { (Importan } \\
\text { ce) }\end{array}$ & $\begin{array}{l}\text { Standar } \\
\text { Reliabili } \\
\text { tas }\end{array}$ & $\begin{array}{l}\text { Keteran } \\
\text { gan }\end{array}$ \\
\hline \multirow{3}{*}{$\begin{array}{l}\text { Bukti } \\
\text { Langsung } \\
\text { (Tangible) }\end{array}$} & 0.955 & 0.908 & 0.60 & Reliabel \\
\hline & 0.953 & 0.901 & 0.60 & Reliabel \\
\hline & 0.956 & 0.914 & 0.60 & Reliabel \\
\hline \multirow{4}{*}{$\begin{array}{l}\text { Kehandalan } \\
\text { (Reliability) }\end{array}$} & 0.953 & 0.899 & 0.60 & Reliabel \\
\hline & 0.952 & 0.904 & 0.60 & Reliabel \\
\hline & 0.953 & 0.905 & 0.60 & Reliabel \\
\hline & 0.955 & 0.903 & 0.60 & Reliabel \\
\hline \multirow{3}{*}{$\begin{array}{c}\text { Ketanggapan } \\
\text { (Responsive } \\
\text { ness) }\end{array}$} & 0.954 & 0.904 & 0.60 & Reliabel \\
\hline & 0.955 & 0.905 & 0.60 & Reliabel \\
\hline & 0.954 & 0.901 & 0.60 & Reliabel \\
\hline \multirow{4}{*}{$\begin{array}{c}\text { Jaminan } \\
\text { (Assurance) }\end{array}$} & 0.955 & 0.901 & 0.60 & Reliabel \\
\hline & 0.952 & 0.904 & 0.60 & Reliabel \\
\hline & 0.956 & 0.904 & 0.60 & Reliabel \\
\hline & 0.954 & 0.893 & 0.60 & Reliabel \\
\hline \multirow{4}{*}{$\begin{array}{c}\text { Empati } \\
\text { (Empathy) }\end{array}$} & 0.954 & 0.891 & 0.60 & Reliabel \\
\hline & 0.953 & 0.896 & 0.60 & Reliabel \\
\hline & 0.953 & 0.894 & 0.60 & Reliabel \\
\hline & 0.952 & 0.904 & 0.60 & Reliabel \\
\hline
\end{tabular}

Berdasarkan uji reliabilitas yang dilakukan dengan menggunakan bantuan software IBM SPSS Statistic 24, yang dijalankan pada laptop dengan prosesor intel core i-3, $1.7 \mathrm{GHz}, \mathrm{RAM} 2 \mathrm{~GB}$ dan 500 GB HDD. Dapat dilihat bahwa 18 atribut yang ada reliabel untuk diggunakan.

\subsection{Perhitungan Tingkat Kesesuaian}

Perhitungan tingkat kesesuaian dilakukan untuk mengetahui tingkat kepuasan pelanggan terhadap pelayanan yang ada. Perhitungan untuk mencari nilai total dari importance dan performance dilakukan dengan bantuan formula yang ada di software microsoft excel, dengan nilai total importance sebesar 7818 dan nilai total performance sebesar 6613. Untuk mencari tingkat kesesuaian digunakan rumus pada persamaan (2.4), dengan perhitungan sebagai berikut 


$$
\begin{gathered}
T_{k i}=\frac{6613}{7818} \times 100 \% \\
T_{k i}=0,84 \times 100 \% \\
T_{k i}=84 \%
\end{gathered}
$$

Berdasarkan perhitungan yang telah dilakukan, tingkat kesesuaian adalah sebesar $84 \%$, artinya mahasiswa sangat puas dengan pelayanan yang ada di universitas, karena kriteria tingkat kepuasan pelanggan berada pada $0.81-1.00$ atau $81 \%-100 \%$

\subsection{Analisis Importance Performance}

Importance Performance Analysis digunakan untuk mengukur suatu elemen yang memperngaruhi kepuasan pelanggan dengan memasukkan nilai-nilai yang didapat ke dalam diagram 2 dimensi, yaitu diagram kartesius, dimana diagram ini mempunyai 4 kuadran. Hasil dari pengolahan kuesioner untuk mencari rata-rata dari tingkat kepentingan mahasiswa dan tingkat layanan dari pihak Universitas Katolik De La Salle Manado, akan dimasukan ke dalam diagram kartesius yang memiliki 4 kuadran, untuk mengetahui atribut apa saja yang harus diperbaiki oleh pihak universitas, karena mahasiswa merasa kurang puas dengan pelayanan dari universitas, apa yang harus dipertahankan oleh pihak univeritas karena mahasiswa sudah merasa puas dengan pelayanan yang ada. Hasil perhitungan rata-rata tingkat kepentingan, tingkat pelayanan/kinerja dari Universitas Katolik De La Salle Manado dapat dilihat pada tabel 5 .

\begin{tabular}{|c|c|c|c|c|}
\hline \multirow[b]{2}{*}{ No } & \multirow[b]{2}{*}{ Dimensi } & \multirow[b]{2}{*}{ Atribut } & \multicolumn{2}{|c|}{ Rata - Rata } \\
\hline & & & $\begin{array}{l}\text { Performance } \\
\qquad(\mathrm{Xi})\end{array}$ & $\begin{array}{c}\text { Importance } \\
(\mathrm{Yi})\end{array}$ \\
\hline 1 & \multirow{3}{*}{ Tangibles } & A1 & 3.9 & 4.8 \\
\hline 2 & & A2 & 3.73 & 4.7 \\
\hline 3 & & A4 & 4.1 & 4.4 \\
\hline 4 & \multirow{4}{*}{ Reliability } & A5 & 3.96 & 4.63 \\
\hline 5 & & A6 & 3.79 & 4.7 \\
\hline 6 & & A7 & 3.81 & 4.7 \\
\hline 7 & & A8 & 3.6 & 4.72 \\
\hline 8 & \multirow{3}{*}{ Responsiveness } & A10 & 4.08 & 4.77 \\
\hline 9 & & A11 & 4.2 & 4.76 \\
\hline 10 & & A12 & 4.18 & 4.55 \\
\hline
\end{tabular}

Tabel 5. Nilai rata-rata Importance-

\begin{tabular}{|c|c|c|c|c|}
\hline \multirow[b]{2}{*}{ No } & \multirow[b]{2}{*}{ Dimensi } & \multirow[b]{2}{*}{ Atribut } & \multicolumn{2}{|c|}{ Rata - Rata } \\
\hline & & & $\begin{array}{l}\text { Performance } \\
\text { (Xi) }\end{array}$ & $\begin{array}{c}\text { Importance } \\
(\mathrm{Yi})\end{array}$ \\
\hline 11 & \multirow{4}{*}{ Assurance } & A13 & 3.73 & 4.68 \\
\hline 12 & & A14 & 3.86 & 4.59 \\
\hline 13 & & A15 & 3.86 & 4.35 \\
\hline 14 & & A16 & 3.74 & 4.50 \\
\hline 15 & \multirow{4}{*}{ Empathy } & A17 & 3.87 & 4.49 \\
\hline 16 & & A18 & 4.14 & 4.6 \\
\hline 17 & & A19 & 3.94 & 4.53 \\
\hline 18 & & A20 & 4.07 & 4.69 \\
\hline
\end{tabular}
Performance
Pada tabel 5 menampilkan hasil nilai rata-rata dari Performance dan Importance, setelah nilai ratarata dari Performance dan Importance didapatkan, maka hasil tersebut akan dimasukan ke dalam diagram kartesius, dimana diagram ini mempunyai 4 kuadran, yaitu kuadran A prioritas utama (Concentrate Here), kuadran B pertahankan prestasi (Keep Up The Good Work), kuadran C prioritas rendah (Low Priority) dan kuadran D berlebihan (Possibly Overkill). Nilai yang akan di masukkan ke dalam diagram kartesius, dimkasudkan untuk mengetahui atribut apa saja yang masuk dalam kuadran A, kuadran B, kuadran C, dan kuadran D. Untuk diagram kartesius selengkapnya dapat dilihat pada gambar 6 .

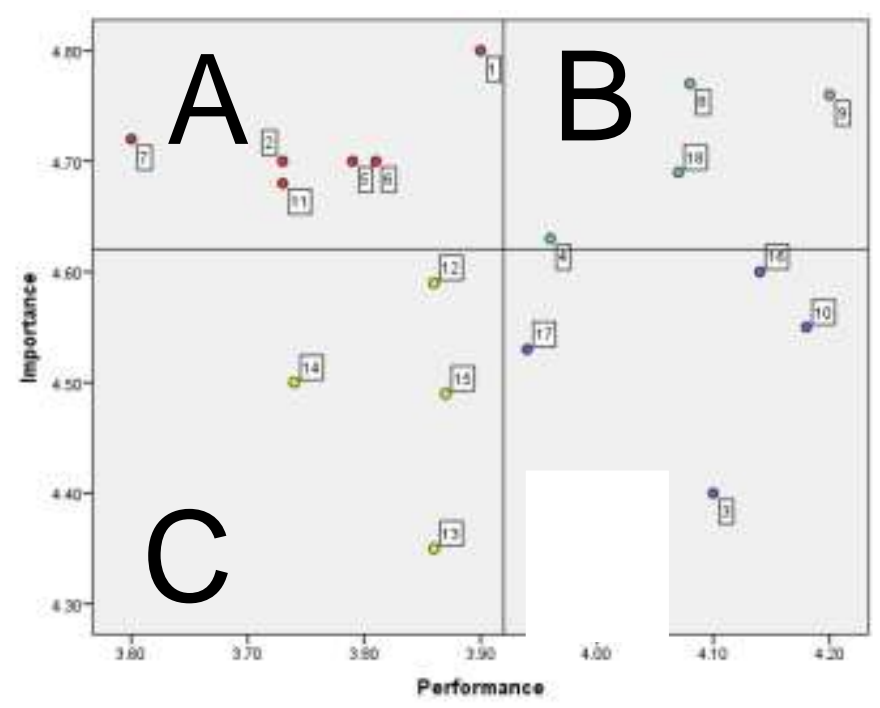

Gambar 6. Diagram Kartesius

- Kuadran A Prioritas Utama (Concentrate Here) 
Pada kuadran ini menunjukkan apa yang dianggap penting oleh mahasiswa, tetapi kurang mendapat perhatian dari Universitas Katolik De La Salle Manado, sehingga kinerja dari Universitas pada variabelvariabel ini di nilai kurang memuaskan. Variabel pada kuadran ini adalah sebagai berikut :

1. Atribut 1 : Ketersediaan sarana prassarana akademik yang memadai (LCD, penghapus papan, spidol, dll)

2. Atribut 2 : Ketersediaan sarana prasarana non akademik yang memadai (tempat parkir, tempat olahraga, toilet, tempat makan, ruang tunggu, dll)

3. Atribut 6 : Kenyamanan pada saat pelayanan administrasi akademik

4. Atribut 7 : Penyimpanan arsip atau dokumen mahasiswa dengan baik dan terstruktur

5. Atribut 8 : Pelayanan yang cepat dan tepat (bagian keuangan, bagian akademik)

6. Atribut 13 : Pelayanan yang santun di beberapa bagian (bagian keuangan, bagian akademik)

- Kuadran B Pertahankan Prestasi (Keep Up The Good Work)

Pada kuadran ini menunjukkan variabel yang menurut mahasiswa sudah dilaksanakan dengan baik oleh Universitas Katolik De La Salle Manado sehingga mahasiswa merasa puas, dan pihak universitas harus mempertahankan kinerjanya. Variabel pada kuadran ini adalah sebagai berikut :

1. Atribut 5: Proses pembayaran yang mudah

2. Atribut 10 : Dosen bersedia membantu mahasiswa/i yang mengalami kesulitan di bidang akademik

3. Atribut 11: Universitas menyediakan beasiswa bagi mahasiswa yang kurang mampu

4. Atribut 20 : Universitas bertanggung jawab atas keamanan dan kenyamanan mahasiswa

- Kuadran C Prioritas Rendah (Low Priority) Pada kuadran ini menunjukkan variabel yang dirasa mahasiswa memiliki tingkat kepentingan rendah, dan kinerja yang dilaksanakan oleh pihak universitas dengan cukup baik, dan tidak perlu mendapatkan perhatian lebih. Variabel pada kuadran ini adalah sebagai berikut :
1. Atribut 14 : Menjelaskan prosedur akademik dengan jelas

2. Atribut 15 : Setiap ujian, quiz, tugas dikembalikan kepada mahasiswa

3. Atribut 16 : Keramahan para petugas security, cleaning service, pelayan foodcourt

4. Atribut 17 : Universitas berusaha memahami minat dan bakat mahasiswa dan berusaha untuk mengembangkannya

- Kuadran D Berlebihan (Possibly Overkill) Pada kuadran ini terdapat variabel yang dianggap tidak terlalu penting oleh mahasiswa, namun kinerjanya sangat baik. Variabel pada kuadran ini adalah sebagai berikut :

1. Atribut $4:$ Kerapihan dosen/staff

2. Atribut 12 : Dosen memberikan waktu tanya jawab

3. Atribut 18 : Dosen/staff berkomunikasi yang baik dengan mahasiswa

4. Atribut 19 : Dosen bersikap terbuka dan koopertif dengan mahasiswa

\section{KESIMPULAN}

Berdasarkan pengolahan dan analisis data yang sudah dilakukan, maka dapat ditarik kesimpulan sebgai berikut :

1. Tingkat kepuasan mahasiswa terhadap pelayanan yang ada di Universitas Katolik De La Salle Manado adalah sebesar 84\%, artinya secara keseluruhan mahasiswa sudah merasa sangat puas dengan pelayanan yang ada di universitas

2. Walaupun tingkat kepuasan mahasiswa termasuk pada kriteria sangat puas yaitu $84 \%$, ada juga atribut-atribut yang harus diperbaiki oleh pihak Universitas Katolik De La Salle Manado karena mahasiswa merasa kurang puas terhadap atribut tersebut. Atribut yang menjadi prioritas utama dan perlu ditingkatkan kinerjanya adalah atribut yang terdapat pada kuadran A, atribut yang sudah baik kinerjanya dan harus dipertahankan yang terdapat pada kuadran B, atribut yang dianggap kurang penting namun kinerjanya sudah cukup baik terdapat pada kuadran $\mathrm{C}$, dan atribut yang dianggap tidak terlalu penting namun kinerjanya sudah sangat baik, dapat dilihat pada diagram kartesius, yang ada pada analisis importance performance.

3. Berdasarkan analisis yang dilakukan, mahasiswa merasa kurang puas terhadap 
beberapa atribut yang ada, salah satunya adalah ketersediaan sarana prasarana akademik yang memadai (LCD, spidol, penghapus papan, meja dan kursi belajar, dll), dimana dengan memperhitungkan dana yang ada, sebaiknya pihak universitas lebih memperhatikan sarana prasarana yang mendukung proses belajar mengajar, menyediakan spidol di setiap ruangan kelas, menyediakan penghapus papan tulis di setiap kelas, mengganti kursi dan meja belajar yang sudah rusak, untuk selengkapnya dapat dilihat pada analisis importance performance.

\section{DAFTAR PUSTAKA}

[1] Teknikelektronika.com. 2017. Cara Menentukan Jumlah Sampel Dengan Rumus Slovin. Available $a t$ http://teknikelektronika.com/caramenentukan-jumlah-sampel-dengan-rumusslovin/.

[2] Ong, J., Pambudi, J. 2014. Analisis Kepuasan Pelanggan Dengan Importance Performance Analysis Di SBU Laboratory Cibitung PT Sucofindo (Persero). J@ti Undip. Vol. 9, No. 1, Hal. 2-9

[3] Anggriani, L., Deoranto, P., Ikasari,D. 2014. Analisis Persepsi Konsumen Menggunakan Metode Importance Performance Analysis Dan Customer Satisfaction Index. Available at jurnalonline.itenas.ac.id/index.php/rekaintegra /article/.../279/524. 